\title{
Learning to recalibrate the role of dead reckoning and visual cues in spatial navigation
}

\author{
ARIANE S. ETIENNE, SYLVIE JORIS LAMBERT, \\ BENOIT REVERDIN, and EVELYNE TERONI \\ University of Geneva, Geneva, Switzerland
}

\begin{abstract}
In Experiment 1, hamsters started from their permanent home at the periphery of a circular arena and headed to a food source at the center. They then returned, fully laden with food, along a direct path to their home. On control trials, in which no manipulation takes place, visual cues outside the arena and dead reckoning (i.e., updated internal references generated during the outward journey to the food source) controlled the return journey. On experimental trials, the arena, with the hamster in its nest, was rotated by $90^{\circ}$, putting dead reckoning at variance with the distal visual environment. The animals were rewarded for going with dead reckoning. At first, they favored the distal cues, but later most of the subjects switched to using dead reckoning. Thus, hamsters are flexible enough to recalibrate the relative weight that they normally attribute to different sets of spatial cues. In Experiment 2, the reliance on dead reckoning was greatly enhanced when a cue card at the nest entrance was rotated along with the arena, pitting one proximal cue plus dead reckoning against distal cues. Hence, dead reckoning and external cues seem to reinforce each other through their mutual correlation.
\end{abstract}

Myomorph rodents may use a variety of different spatial cues to navigate within a familiar environment, depending on the availability of stimuli from the proximal or distant environment (for a summary of behavioral and neuropsychological literature, see Leonard \& McNaughton, 1990; O'Keefe \& Nadel 1978; Olton, 1979; Olton, 1990; Restle, 1956). In the absence of adequate external information, the subject may rely entirely on selfgenerated signals originating from antecedent locomotion. This category of spatial information corresponds either to the long-term storage of a fixed sequence of responserelated (re)afferences (Watson, 1907) or to dead reckoning. In the latter case, the subjects continuously update internal signals that derive from the angular and linear components of their locomotion; through this process of path "integration"' (Mittelstaedt \& Mittelstaedt, 1982), they remain constantly informed on their location with respect to a fixed point of reference, whence they started to generate and update path-dependent information. Dead reckoning may therefore play an important role in spatial orientation (Gallistel, 1990)-in particular, in homing, when the animal has to return to the very point in

This research was supported by Swiss NSF Grant $31-26227.89$. We wish to thank Roland Maurer for his help in the evaluation of the results, Raynald Schumacher for his technical assistance, and Alex Kfouri, Marcia L. Spetch, Vincent M. LoLordo, and an anonymous referee for their helpful suggestions concerning a first and second version of the manuscript. Special thanks are due to Ken Cheng for his critical comments. The authors are affiliated with the Laboratory of Ethology, FPSE, University of Geneva, 54 rte des Acacias, 1227 Carouge, Geneva, Switzerland. Correspondence should be addressed to A. S. Etienne, 31 Ecorcherie, 1253 Vandoeuvres, Switzerland. space from which it has initiated its excursion away from "home" (Etienne, 1992).

If we assume that, during locomotion, dead reckoning always takes place through the automatic activation of an internal navigation system (O'Keefe \& Nadel, 1978), its outcome must interact with external spatial cues that the subject encounters while proceeding through familiar space. Dead reckoning depends both on peripheral (and maybe central) feedback information from locomotion and on vestibular signals. Since vestibular information is caused by inertial forces, dead reckoning is measured with respect to a fixed earthbound coordinate system and must therefore correlate with prominent stable features in the known environment. Obviously, the spatial relevance of these features can be enhanced through their correlation with positional information deriving from dead reckoning.

Our general study concerns the control exerted by different categories of spatial information on short-distance homing in the golden hamster during food hoarding. In our standard test conditions, the animal proceeds from its nest (at the arena periphery) to a food source (at the arena center) and then returns, fully laden with food, along a fairly direct path to its nest. If we rotate the arena (and nest box) before the beginning of a particular hoarding excursion so that the subjects have to start the outward journey to the food source from an unusual point at the arena periphery, the animals' subsequent homing direction depends on the visual test conditions.

Under infrared light, the subjects return to the new angular position of the nest-that is, to the very point in absolute space from which they initiated the outward journey. Within certain limits, the direct return to the starting 
point of each hoarding excursion occurs independently of the particular path that the subject followed to reach the feeding place during the outward journey (Etienne, Maurer, \& Saucy, 1988). Convergent results from different experiments suggest that the homing direction is not based on (rotated) cues from within the arena but depends on the updating of the outward journey through the process of dead reckoning. In our experimental conditions, this process is initiated at the nest exit and therefore does not take into account vestibular information originating from the initial rotation of the nest box. Furthermore, it does not occur with respect to a reference from the environment but is carried out on purely self-generated (i.e., mainly proprioceptive and vestibular) signals.

When the same experiment takes place under ordinary roomlights, the hamsters' homing path is mainly directed toward the usual or standard angular position of the nest. Now, stable visual cues from outside the arena, which the animal has previously associated with the standard nest direction (or location), play a predominant role. At the same time, however, the return trips are slightly deviated toward the new, rotated position of the nest and therefore express the concomitant influence of dead reckoning, which always occurs (Teroni, Portenier, \& Etienne, 1987).

The research that is presented in this paper originated from the observation that in the above-mentioned conflict situation between dead reckoning and distant visual cues, the influence of dead reckoning may be strengthened through the presentation of a conspicuous cue card within the arena. During the experimental trials, this proximal cue is rotated with the arena (and nest) and therefore always remains correlated with dead reckoning. Furthermore, both dead reckoning and the intramaze cue lead the animal to its goal-the nest entrance. In these conditions, hamsters seem to learn easily to return toward the new, rotated position of the nest, despite the strong impact of distant visual cues. The question therefore arose whether the same learning process can also take place when the hamsters cannot rely on a distinctive cue within the arena. So far, our results had excluded this possibility, most likely for reasons linked to our experimental technique (Teroni et al., 1987). We therefore changed the experimental protocol and trained the animals during a prolonged period of time to rely on dead reckoning rather than on distal visual cues-that is, to change the order of priority that they normally give to different classes of spatial information.

This paper is organized in the following manner:

1. Learning experiments in which the animals had to recalibrate the relative influence of extramaze cues and dead reckoning without being aided by an intramaze cue are presented first.

2. We then describe experiments that involved the presentation of a conspicuous intramaze card around the nest entrance.

3. In former experiments, the same intramaze cue had been presented either around the nest entrance, or at an angular distance of $90^{\circ}$ from it; the results of these ex- periments are summarized and compared with those of Experiment 2.

The results of the present experiments are discussed with respect to the interaction between dead reckoning and distal or proximal visual cues, to the animals' capacity to change their relative dependence on these cues, and to the literature on the spatial significance of extramaze and intramaze cues.

\section{EXPERIMENT 1 Learning to Rely on Dead Reckoning Rather Than on Distal Visual Cues}

In previous experiments that took place under ordinary roomlight, involving a $90^{\circ}$ rotation of the arena, the arena and nest box were rotated back into their usual position as soon as the subject had reached the arena periphery during the return journey from the feeding place at the center. Thus, in all trials, the animal ended up by finding the nest entrance at the expected location by means of distant visual configurations. Under these conditions, the animals did not change their homing behavior and continued to rely mainly on the distant visual environment to home throughout the test period, which generally involved 20 control (no rotation) and 20 experimental (10 clockwise and 10 counterclockwise rotations) trials (Teroni et al., 1987). We examined, therefore, whether hamsters may learn to give priority to dead reckoning rather than to distal visual cues if the arena is left in its new, rotated position until the animals have found the nest entrance. In these conditions, dead reckoning leads the animals home, whereas the distant visual environment leads them astray.

\section{Method}

Subjects. The subjects were 12 golden hamsters (Mesocricetus auratus W.), all adult females, that had been bred in our laboratory. In general, the subjects had been used during a limited time span in a former experiment that involved the same experimental arena but a different visual background. Each animal was therefore introduced into the experimental arena at least 5 days before the beginning of the experiment. It lived there alone throughout the period during which it was tested. The hamsters were kept under an artificial light cycle (dark phase: $4: 30$ p.m. to $4: 30$ a.m., or 6:45 p.m. to 6:45 a.m.) and tested at the beginning of the dark phase. Since the experiments took place under ordinary roomlights, the light phase was extended during the late afternoons or early evenings in which the experiment took place. The subjects were fed ad lib with a variety of different food items.

Apparatus. The experimental arena is depicted in Figure 1. A nest box was attached to the arena wall at a constant position with respect to geographic north when the arena was in its standard position (i.e., when it was not rotated). The subject established its granary within the nest box. Between the test sessions, the animal could move freely between the nest and the arena by pushing a circular door at the nest entrance. For reasons of symmetry, 11 other doors were evenly spaced around the arena periphery.

The arena was located in a large experimental room $(8.5 \times 4.5$ $\times 3.2 \mathrm{~m}$ ), which provided the subjects with a variety of asymmetrical extramaze cues. Along its long axis, the experimental room contained a second arena, which was surrounded by a white enclosure. The walls next to the arena differed in their brightness-two of them had a door, and the third one had two (sealed) windows. The ceil- 


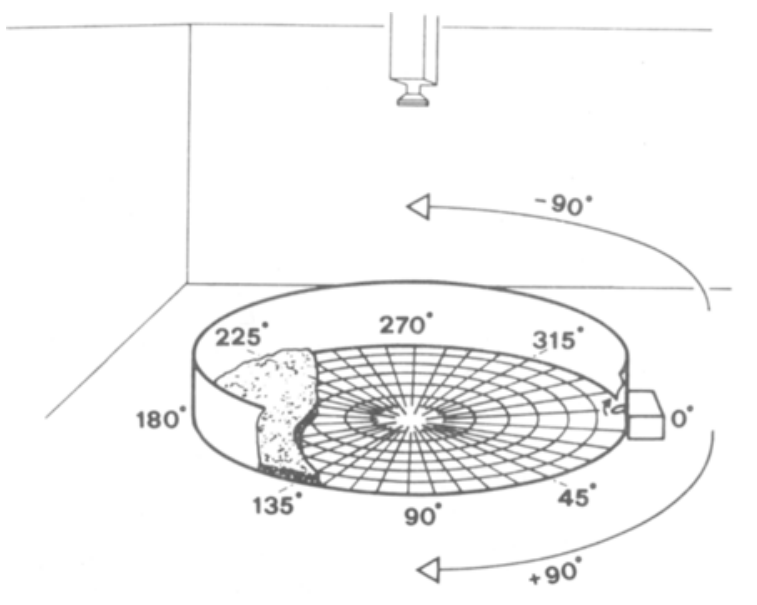

$1 \mathrm{~m}$

Figure 1. Apparatus and procedures. Each subject lived alone in the experimental arena $(r: 110 \mathrm{~cm}$; height of peripheral wall: $30 \mathrm{~cm})$. The nest box $(35 \times 17 \times 10 \mathrm{~cm})$ was attached to the outer wall of the arena and is shown here in its standard position $\left(0^{\circ}\right)$ to the right. By pushing a small circular door hinged at the top (see small arrow), the animal passed back and forth between the nest and the arena. The floor of the arena was covered by a thick layer of sawdust, which was stirred at regular intervals. The subjects' paths on the arena floor were coded with respect to thirty-six $10^{\circ}$ sectors (center line of Sector $1=0^{\circ}$ ) and to six annular zones of $15-\mathrm{cm}$ width. The complete hoarding trips were recorded by a video camera placed above the center of the arena. In Experiment 2, a white plastic sheet subtending a $30^{\circ}$ arc was attached to the black arena wall around the nest entrance. During the experimental trials, the arena (and nest box) was rotated $90^{\circ}$ (clockwise or counterclockwise) from its standard position (see large arrows around arena) before the subject had left the nest. In all of the trials, the reference direction $\left(0^{\circ}\right)$ points to the standard location of the nest entrance.

ing, too, was (asymmetrically) patterned by two rows of fluorescent lights and a rail system on which the video camera could be displaced along the long axis of the room.

Procedure. Only 1 hamster was tested during a particular period in one of the two arenas that were used throughout in these experiments. Thus, all animals had the same view of the environment from outside the arena. Before the beginning of the experiments, the subjects were induced to hoard food from within the arena and to bring it back to their nest box. Only those subjects that established their granary within the nest box and, because of an intense motivation for hoarding, immediately started to pouch food items at the feeding place (and therefore did not wander about in the arena upon their arrival at the food source), were retained for the experiment. Furthermore, during preliminary tests as well as during the entire experimental period, the animals had to direct their return journeys toward the (usual) nest site as long as the arena had not been rotated, despite the fact that nothing hindered the hamsters from returning home along an indirect path. From a total number of 12 subjects that had been introduced into the experimental arena, 4 animals did not fulfill the initial test conditions, and two other animals became disoriented in the control trials of the experimental training period. Let us mention here that in all of our experiments that test homing behavior in the hoarding situation, a considerable proportion of hamsters have to be discarded during the preliminary test phase because the test conditions are extremely demanding.
One hoarding trip represented the fundamental unit of our experiments: During the outward journey, the subject was either led (by tapping a stick along the path) or went spontaneously from its nest exit to a food source (hazelnuts) at the center of the arena. There it filled its cheek pouches, generally by turning around the food heap. Fully laden with food, the animals returned along a direct route to the arena periphery, where they found the nest entrance either immediately or after searching around the wall of the arena.

During the daily test sessions, the animals underwent one or two series of eight trials. The intertrial interval varied between 30 and $60 \mathrm{sec}$. The control trials lasted $25-55 \mathrm{sec}$, with interindividual differences depending mainly on the duration of the outward journey and on the rhythm of food pouching and intraindividual variations deriving rather from the search for the nest entrance at the periphery of the arena. Until the subjects had reached the learning criterion, the experimental trials lasted longer than the control trials, with the subjects starting to search for the nest entrance in its standard angular position and therefore taking more time to find it in its new position (see the Results section). In the four control trials of each series, the arena was left in its standard $0^{\circ}$ position. In the experimental trials, the arena (and nest box) was rotated clockwise or counterclockwise by $90^{\circ}$ before the animal had left the nest exit. Thus, the subject approached the arena center from a different starting point in absolute space. During the subject's return, the arena was left in its new, rotated position either until the animal had found the nest entrance or for a maximum interval of $3 \mathrm{~min}$ after the subject had reached the arena periphery. Thereafter, the arena was rotated back into its standard position.

Six different test series were determined. In all series, there was a regular alternation between the control and experimental trials. In contrast, the clockwise and counterclockwise experimental trials followed each other according to a particular pseudorandom sequence in each series.

Before each experimental series of eight trials, the sawdust on the arena was stirred and flattened out again in order to eliminate olfactory and tactile trails. Since static distant odors do not allow a subject to orient itself menotactically, the animals were not expected to use olfactory cues originating from the nest or from markings around the peripheral wall of the arena before they reached the peripheral annular zone. Acoustical and geomagnetic cues did not seem to influence the animals' homing behavior in our testing condition and therefore were not altered (Etienne, Maurer, Saucy, \& Teroni, 1986).

One experimenter remained within the experimental room throughout each test series. The experimenter's role was to rotate the arena back and forth, to release the subject from its nest at the beginning of a hoarding excursion, and to lead it, if necessary, to the food source. In successive trials, the experimenter changed his or her position at the arena periphery. As soon as the animal had approached the food source in each particular trial, the experimenter hid behind the arena wall.

The hoarding excursions of the subjects were filmed by a video camera that was moved along a rail above the arena center at the beginning of each experimental session. To code the return path from the center to the periphery of the arena, the floor of the arena was subdivided in $10^{\circ}$ sectors (see Figure 1), with the center line of Sector 1 at $0^{\circ}$ and the sectors numbered clockwise from 1 to 36. These subdivisions were also superimposed on the video screen. For each return, we noted in which $10^{\circ}$ sector each subject crossed in succession the six concentric circles on the arena floor. Since the subjects proceeded in a fairly straight line from the center to the periphery of the arena, the results are presented with respect to only the final orientation of the animals-that is, at the moment when they crossed the largest concentric circle (at a distance of $15 \mathrm{~cm}$ from the arena wall) and thus entered the peripheral annular zone of the arena. To see whether the orientation and position of the animal just before it started a particular return path influenced the homing direction, we noted in which $10^{\circ}$ sector the sub- 
ject was located when it pouched the last items at the center of the arena before initiating the homing path. We also measured the time the animal took to reach the nest entrance from the food source at the arena center.

In the evaluation of the experimental trials, we assumed that if the animal entered the peripheral annular zone of the arena in a $90^{\circ}$ sector centered on $0^{\circ}$, it had relied predominantly on visual configurations from outside the arena. Correspondingly, we assumed that the subject had reached the criterion for depending on dead reckoning when it reached the peripheral annular zone in a $90^{\circ}$ sector with a center line of either $+90^{\circ}$ (clockwise rotation) or $270^{\circ}$ (counterclockwise rotation of arena). This means that in order to satisfy the criterion for returning toward the rotated nest, the subject had to reach the arena periphery in Sectors 6 to 14 during clockwise rotations, and in Sectors 24 to 32 during counterclockwise rotations. In Figures 3, 4, and 8, these critical limits, as well as the angular position of the rotated nest entrance, are indicated by long-dashed lines.

We decided that the animals had attained the learning criterion for returning toward the new position of the nest when, during all experimental trials of two successive test series-that is, during eight consecutive experimental trials altogether-they returned toward the $90^{\circ}$ sector that was centered on the rotated nest box. In the text, we often refer to the moment when a subject reached the learning criterion by mentioning only the number of the first of these two consecutive test series. Thus, a subject that started to return during Test Series 8 and 9 in all experimental trials to the $90^{\circ}$ sector that was centered on the nest box is said to have reached the learning criterion during Test Series 8, or after 32 experimental trials.

As in all our experiments that tested the homing direction, testing was interrupted and the subjects were discarded if they did not (or did no longer) direct their return journey toward the nest box in the control situation, when the arena was left in place. It must be stressed that in our experimental conditions, the subjects were completely unrestrained and could return from the center to the periphery of the arena along any direction; they always reached the nest entrance by exploring the peripheral arena wall.

Statistics. Circular statistics (Batschelet, 1981, and personal communication, August 24,1979 ) were used to evaluate the homing directions during the very first control and experimental trials of Experiments 1 and 2 and during the last two test series, in which the subjects had reached the learning criterion. The Rayleigh firstorder test was used to determine if the subjects were significantly oriented during the first control and the first experimental trial of a given experiment (see solid vectors on Figures 2 and 7) and if a particular subject yielded a significant mean direction during repeated trials within particular test conditions (see full arrowheads on Figures 5 and 9). The Wheeler-Watson first-order test was used to compare significant first-order vectors that had been obtained in two different test situations.

Moore's test was used to determine whether the mean direction from particular subjects which were tested repeatedly in the same test situation yielded a significant second-order vector (see large open vectors on Figures 5 and 9).

Nonparametric statistics (Siegel, 1956) were chosen to compare data that did not directly concern the choice of particular homing directions. The Mann-Whitney $U$ test was applied to compare data from the two different experimental groups tested in Experiments 1 and 2 . The results that were obtained from the same subjects in different test situations of Experiments 1 and 2 were compared by means of the Wilcoxon matched-pairs signed-ranks test.

\section{Results and Discussion}

Our 6 subjects behaved as expected during the first experimental trial, which involved a clockwise rotation of the arena (see Figure 2): They returned mainly in the $0^{\circ}$ reference direction toward the arena periphery and there-

$$
0^{\circ}
$$$$
+90^{\circ}
$$
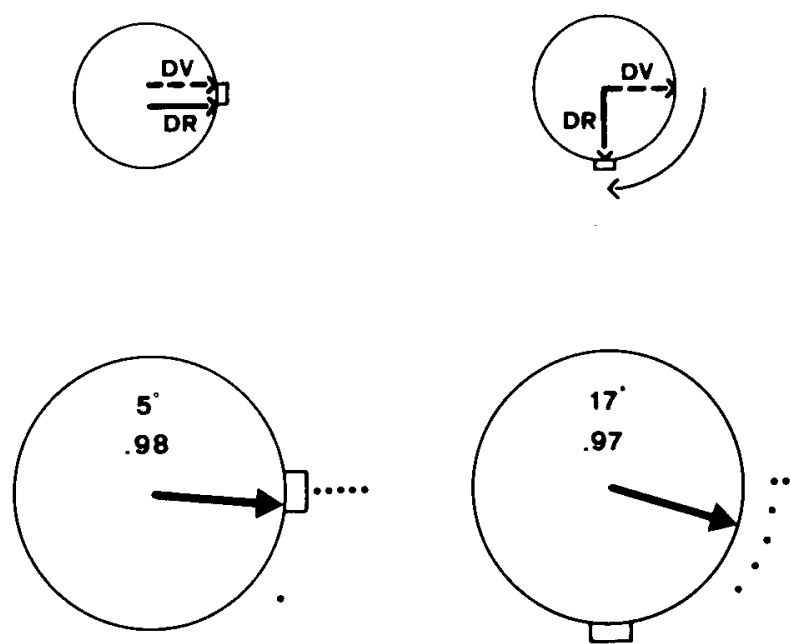

Figure 2. Return directions during the first two trials in Experiment 1 . During the control trial, the arena remained in position $\left(0^{\circ}\right.$, circles at left); during the experimental trial, the arena and nest box were rotated clockwise $\left(+90^{\circ}\right.$, circles at right). In the small circles on top, the arrows indicate the theoretical homing directions the animal would follow if it relied on distal visual cues (DV) or on dead reckoning (DR). In the large circles, the dots indicate in which $10^{\circ}$ sector each subject entered the peripheral annular zone of the arena in the first control trial and in the first experimental trial. The vectors represent the mean homing direction of 6 subjects; the numbers within the circles indicate the deviation of the vector from the $0^{\circ}$ reference direction and the vector length (maximum vector length $=1=$ radius). Both vectors are significant (first-order statistics, $p<.01$; Rayleigh test) and do not differ from each other. The position of the nest box is indicated by the small rectangle.

fore relied on associations between distal room cues and the standard nest location. Four of them, however, also showed a clockwise bias, so that the mean homing direction was slightly deviated toward the actual, rotated position of the nest, from which the subjects had started the outward journey to the food source. This bias expresses the concomitant influence of dead reckoning, which is always at work.

During the entire training period-that is, for a total of 120 experimental trials- 2 of the above-mentioned subjects did not learn to return toward the $90^{\circ}$ sector centered on the rotated nest entrance (see Figure 3). Subject 1 showed compromise behavior and a few full compensations for (counterclockwise) rotations of the arena between Test Series 17 and 21, but thereafter headed mainly toward the standard position of the nest. Subject 2 showed many inversions (i.e., counterclockwise compensation of a clockwise nest rotation and vice versa), and ended up by returning in all trials in a counterclockwise direction with respect to the standard nest location.

Thus, only 4 out of the 6 subjects that could be maintained during the entire experimental period reached the 

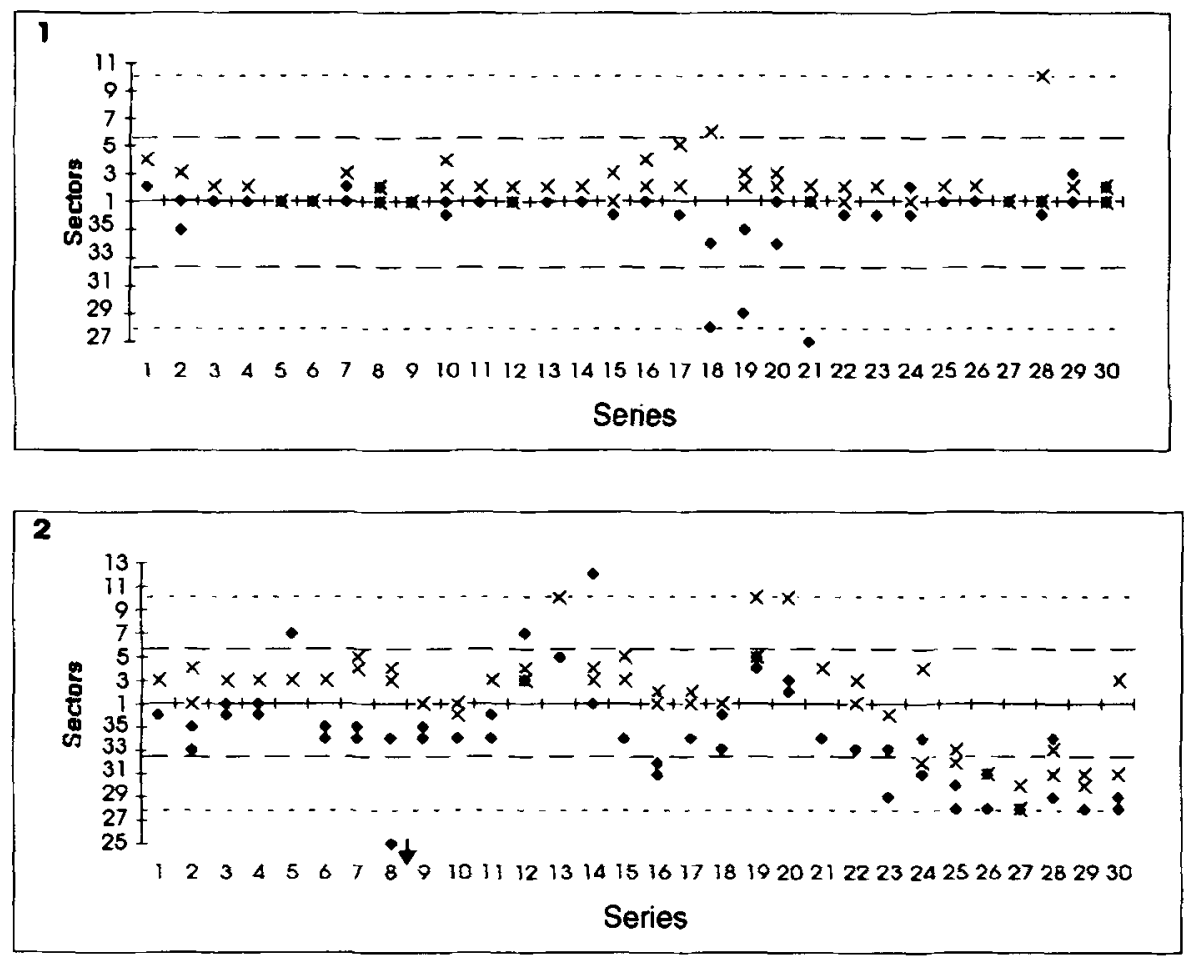

Figure 3. The negative results of the animals' learning to return to the rotated nest in Experiment 1. The two graphs describe the orientation of 2 subjects (1 and 2) that did not reach the learning criterion. The abscissae represent the number of the experimental series, each of which included two trials with a clockwise rotation and two trials with a counterclockwise rotation of the arena and nest box. The ordinates indicate the number of the $10^{\circ}$ sector (in fixed space) in which the animal reached the peripheral annular zone of the arena during clockwise (crosses) or counterclockwise (diamonds) rotations of the arena. The center line of Sector 1 is $0^{\circ}$, and the sectors are numbered clockwise from 1 to 36. The long-dashed lines define the relevant limit (upper line: Sector 6 for clockwise rotations; lower line: Sector 32 for counterclockwise rotations) of the region in which the animal must reach the arena periphery in order to satisfy the criterion for returning toward the rotated nest. The short-dashed lines indicate the angular position of the rotated nest entrance. Symbols near the $0^{\circ}$ line indicate that the subject returned toward the standard location of the nest. Symbols near the long-dashed lines indicate that the subject performed a compromise between the return toward the former and the actual positions of the nest. Symbols near the shortdashed lines indicate that the subject returned toward the new position of the nest. If the animal reached the arena periphery in the same $10^{\circ}$ sector during the two trials with a clockwise (counterclockwise) rotation during the same test series, only one cross (diamond) is represented. The arrow next to a diamond on Graph 2 indicates that the animal reached the arena periphery beyond Sector 25.

learning criterion. This was the case after a mean number of 16.8 test series or of 67.2 experimental trials (range: 44-108 trials). As is shown by Figure 4, the successful animals produced rather irregular learning curves. Before reaching the learning criterion, Subject 2 showed mainly compromise reactions during a number of test series. Subject 3 performed many inversions (see above). Subject 4 learned sooner and more thoroughly to compensate for counterclockwise than for clockwise rotations. Nevertheless, during the attainment of the learning criterion, Subjects 1 and 3 returned in all final trials clearly toward the (rotated) nest entrance, and Subjects 2 and 4 went well beyond compromise behavior. Thus, most of the first-order vectors point toward the nest in Figure 5, and the second-order vectors express only a weak bias, which is still due to the impact of the distant visual environment. From a statistical viewpoint, the learning cri- terion implies by itself that the final distribution of the homing directions in the two (clockwise and counterclockwise) types of experimental trials is quite distinct from the distribution of the return directions during the control trials. Furthermore, the homing directions of the 4 subjects during the first experimental (clockwise) trial differ significantly from their homing directions in the last clockwise experimental trial (first-order statistics, $p<$ .01 ; Wheeler-Watson test).

We do not know whether the learning criterion would have been maintained during additional test series. Only Subject 1 was submitted to further testing after having reached the learning criterion during Series 11 and 12 . It regressed during Series 13 and 15 and reached the learning criterion for the second time during Series 16 and 17 .

As is shown by Figure 6, a decrease in the duration of the return journey took place already after the first test 

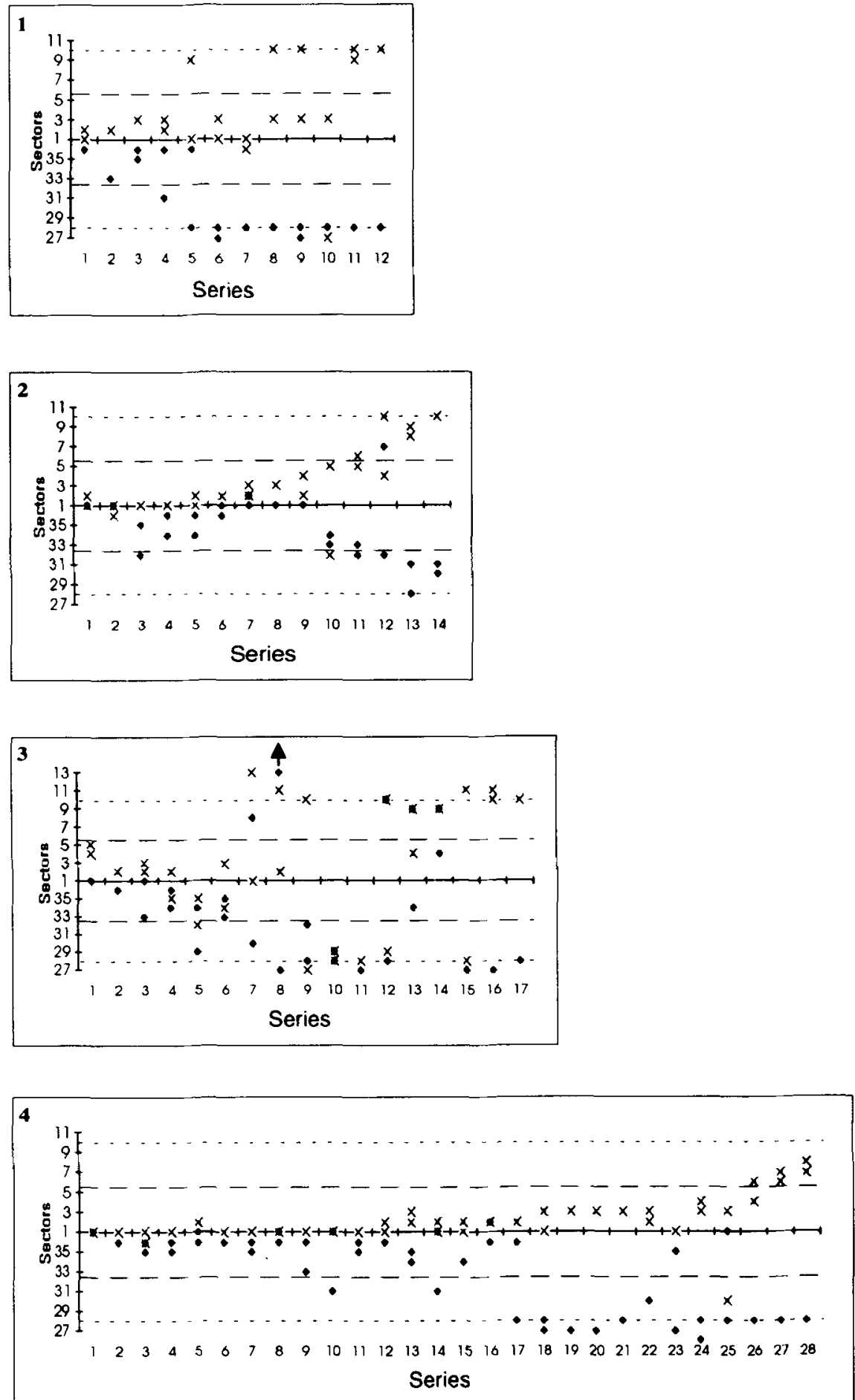

Figure 4. The positive results of the animals' learning to return to the rotated nest in Experiment 1 . The four graphs describe the orientation of 4 subjects $(1-4)$ that reached the learning criterion. The arrow beneath a diamond on Graph 3 indicates that the animal reached the arena periphery beyond Sector 13. For further explanations, see the caption of Figure 3. 


\section{$0^{\circ}$}
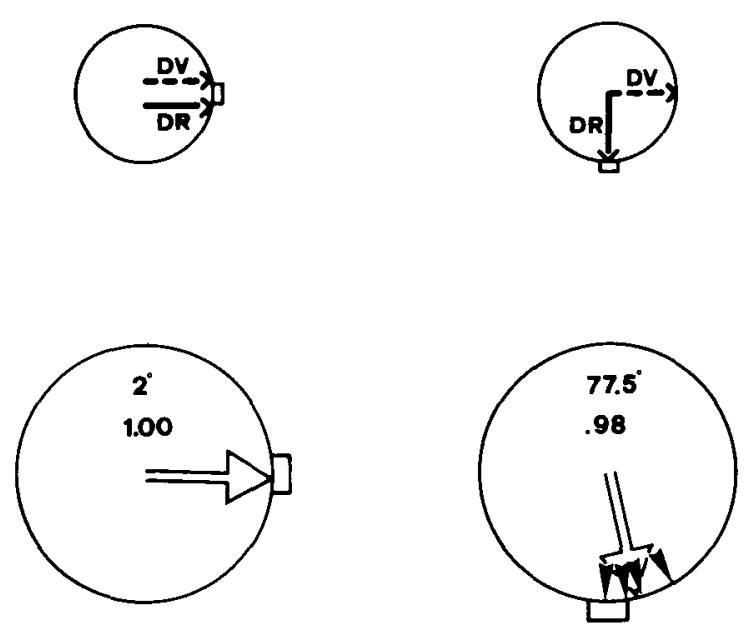

$-90^{\circ}$
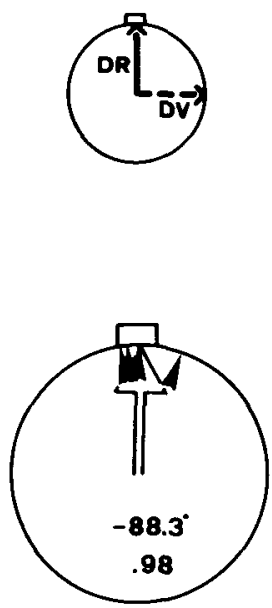

Figure 5. Return directions during attainment of the learning criterion in Experiment 1. During the control trials, the arena remained in position $\left(0^{\circ}\right.$, circles at left); during the experimental trials, the arena and nest box were rotated clockwise $\left(+90^{\circ}\right.$, circles at center) or counterclockwise $\left(-90^{\circ}\right.$, circles at right). On the large circles, the large open vector represents the mean homing direction of 4 subjects during eight control and four experimental trials (second-order statistics, $p<.005$; Moore's test). The numbers within the circles indicate the deviation of this vector from the $0^{\circ}$ reference direction and the vector length. On the two circles to the right, each full arrowhead represents the mean homing direction of one subject during four experimental trials (first-order statistics, $p<$ .01 ; Rayleigh test). Maximum vector length $=1=$ radius. For further explanations, see the caption of Figure 2.

series, before a systematic change in the homing direction could be observed. In fact, this initial decrease in the animals' return time was due mainly to the improvement of their search strategy for the nest entrance along the arena border. The return times decreased to a low final level when the animals returned directly from the arena center toward the rotated nest entrance.

In summary, 4 of the 6 animals that satisfied the experimental criteria (direct return during control trials). learned to return toward the rotated nest location during 8 consecutive experimental trials. These subjects reached the learning criterion after 44 to 108 experimental trials. Thus, our golden hamsters were flexible enough to free themselves from the influence of distant visual cues and to rely mainly on dead reckoning; however, this learning process involved considerable difficulties.

\section{EXPERIMENT 2 \\ Correlating Dead Reckoning With a Proximal Cue}

As already mentioned, the learning experiments of this research originated from preliminary test conditions in which the arena contained a conspicuous intramaze cue. This situation was reproduced in new experiments that are described here. In contrast to Experiment 1, a large white cue card surrounded the nest entrance on the black arena wall throughout the testing period of Experiment 2.
When the arena was rotated, this conspicuous proximal cue underwent the same displacement as did the nest box and therefore always remained correlated with dead reckoning. Furthermore, the (location-based) cue card as well as (route-based) dead reckoning led the animal regularly back to its goal, the nest entrance. Learning to return to the actual, rotated nest entrance could therefore be enhanced by the conjoint influence of dead reckoning and the intramaze cue, both of which were set in conflict with the unrotated distant visual environment.

This section presents mainly recent data that have been obtained in experimental conditions identical to those of Experiment 1, except for the continuous presentation of the cue-card on the internal arena wall. A final paragraph is devoted to "superexperimental" trials, in which the cue card was either removed or no longer superimposed on the nest entrance, so that dead reckoning and the proximal visual cue yielded different directional information. Results from former experiments, which involved a similar proximal cue card but were not carried out according to strictly the same procedures are reported under Supplementary Experiments.

\section{Method}

Subjects. The females that were tested in Experiment 2 were of the same age group, had a comparable experience with former test situations, and were maintained in the same conditions as those of Experiment 1. They were tested in alternation with the subjects of Experiment 1. 


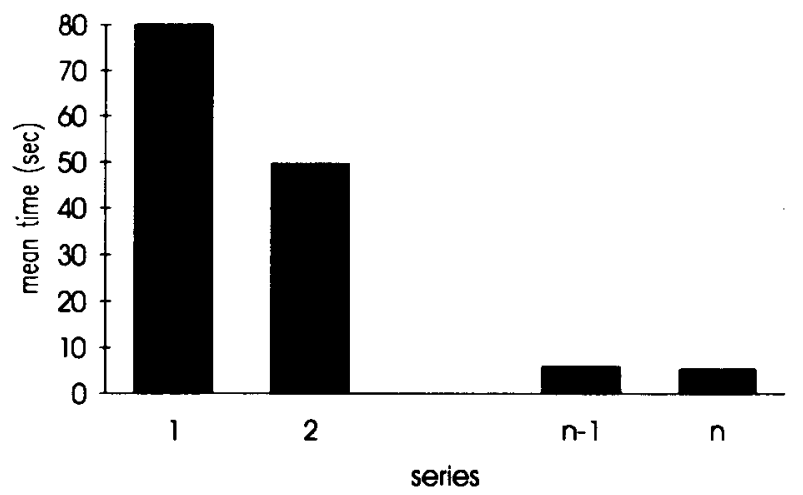

Figure 6. Return times at beginning and end of training in Experiment 1. The histograms represent the mean duration of the return paths performed by 4 subjects during the experimental trials of the first two and the last two test series. Each test series included four experimental trials.

Apparatus. The animals lived and were tested in the same arena as that of Experiment 1 . In contrast to Experiment 1, however, a conspicuous intramaze cue surrounded the nest entrance. The cue consisted of a white plastic rectangle, which subtended $30^{\circ}$ on the (black) arena wall and was of the same height as the wall.

Procedures. The subjects were selected as in Experiment 1 before the beginning of the test period. Out of 16 animals that had been introduced into the arena, 9 had to be eliminated because they did not fulfill the necessary test conditions. One additional animal was discarded because it became disoriented during the control trials of the test period.

The test period was subdivided in three phases. (1) The subjects were tested according to the same procedures as were the subjects of Experiment 1 until they had reached the learning criterion (i.e., until they returned regularly toward the $90^{\circ}$ sector that was centered on the actual position of the nest entrance during two successive test series including 8 experimental trials altogether); (2) to consolidate the learning process, the animals underwent three further test series including 12 experimental trials altogether; and (3) thereafter, they were subjected to six test series, each of which included an additional control trial and a final "superexperimental" trial. The latter involved not only the $90^{\circ}$ rotation of the arena but also a dissociation between the white cue card and the nest entrance (see Figure 11). This dissociation occurred according to three distinct modalities: (a) Before the clockwise (counterclockwise) rotation of the arena, the cue card was displaced by $90^{\circ}$ clockwise (counterclockwise). Thus, after the rotation of the arena, the nest entrance deviated by $90^{\circ}$, and the cue card by $180^{\circ}$ from the standard position of the nest entrance. (b) The cue card was removed before the beginning of the trial. (c) The cue card was displaced by $180^{\circ}$ from its usual position around the nest entrance; after a clockwise (counterclockwise) rotation of the arena, the angular position of the card deviated counterclockwise (clockwise) by $90^{\circ}$ from the standard location of the nest entrance. Each subject was tested twice in each condition, with the arena rotated clockwise or counterclockwise. As hamsters may become confused and show erratic homing behavior when exposed to strongly conflicting spatial cues, care was taken to submit the subjects to only one test series which contained one final superexperimental trial during a particular test session. The order in which the hamsters were presented with each category of superexperimental conditions followed the order of their description above.

\section{Results and Discussion}

During the first experimental trial (clockwise rotation of arena), all but 1 subject appeared to deviate clockwise from the standard nest location (see Figure 7). The comparison between the direction and lengths of the experimental vectors on Figures 2 and 7 seems to indicate that the subjects deviated more from the $0^{\circ}$ reference direction and showed a greater variance in their homing behavior in Experiment 2 than in Experiment 1. Thus, for untrained animals, the combination of the proximal cue card and dead reckoning seemed to exert a stronger effect on homing than did dead reckoning alone. However, the difference between the homing behavior in Experiments 1 and 2 is not significant. The hamsters returned mainly toward the usual nest location and therefore gave priority to distal visual cues, with or without the presentation of the proximal cue.

Figure 8 shows that half of the animals (Subjects 1, 2, and 5) started to return toward the $90^{\circ}$ sector centered on the rotated nest entrance even during Experimental Series 1 . The consolidation of this tendency occured rapidly for Subjects 1 and 2, whereas Subject 5 compensated for
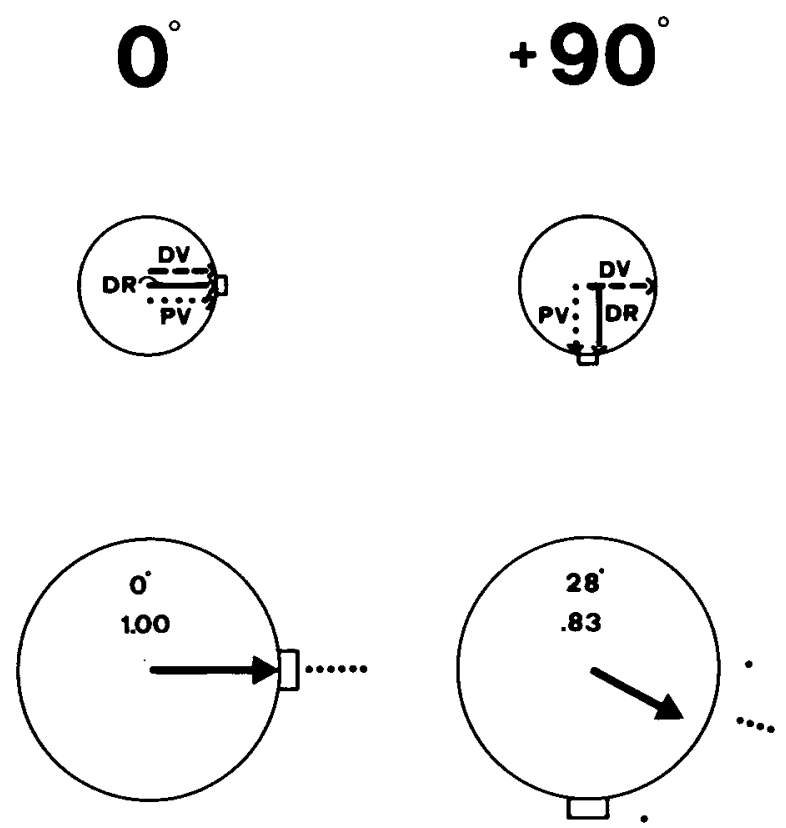

Figure 7. Return directions during the first two trials in Experiment 2 . In the small circles on top, the arrows indicate the theoretical homing directions the animal would follow if it relied on distal visual cues (DV), on the proximal cue card around the nest entrance (PV), or on dead reckoning (DR). In the large circles, the dots indicate in which $10^{\circ}$ sector each subject entered the peripheral annular zone of the arena in the first control and in the first experimental trial. The vectors represent the mean homing direction of 6 subjects (first-order statistics, $p<.01 ;$ Rayleigh test). The control and experimental vectors do not differ from each other. For further explanations, see the caption of Figure 2. 

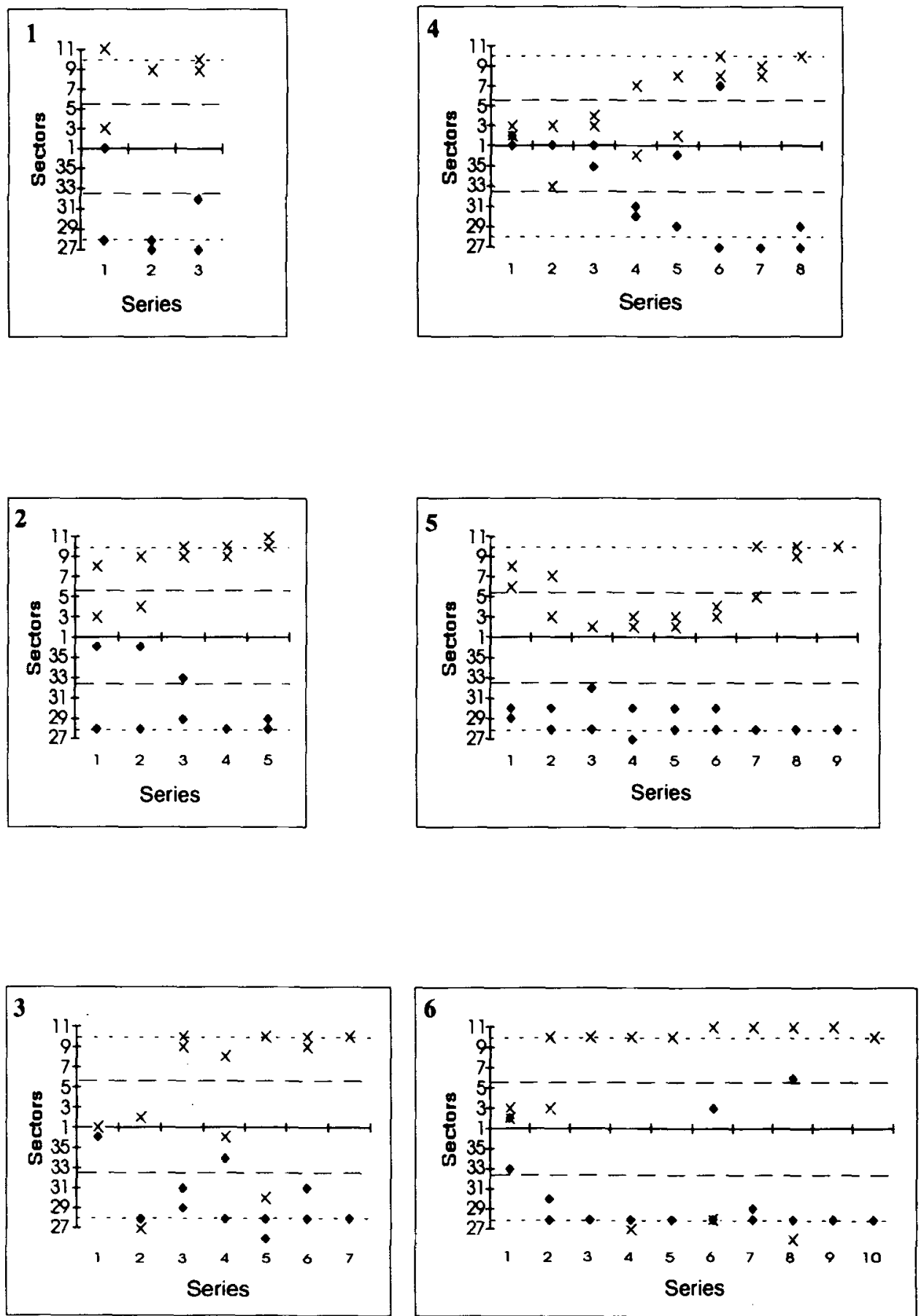

Figure 8. Learning to return to the rotated nest in Experiment 2. Each graph describes the orientation of 1 subject (numbers 1-6) during successive test series. For further explanations, see the caption of Figure 3.

all clockwise rotations of the arena insufficiently during the following 5 test series and reached the learning criterion during Experimental Series 8 and 9 . The other 3 subjects $(3,4$, and 6$)$ started to return toward the rotated nest entrance during Test Series 2 or 4 but thereafter continued to show both occasional undercompensations of the arena rotation and a few inversions.
All 6 subjects reached the learning criterion after a mean number of 6 training series, that is, 24 experimental trials (range: 8-36 trials). During attainment of the learning criterion (see Figure 9), the second-order vectors, which represent the mean direction of the whole experimental group, show almost no bias toward the $0^{\circ}$ reference direction. Again, the subjects reduced rapidly the duration of their 


\section{$0^{\circ}$}
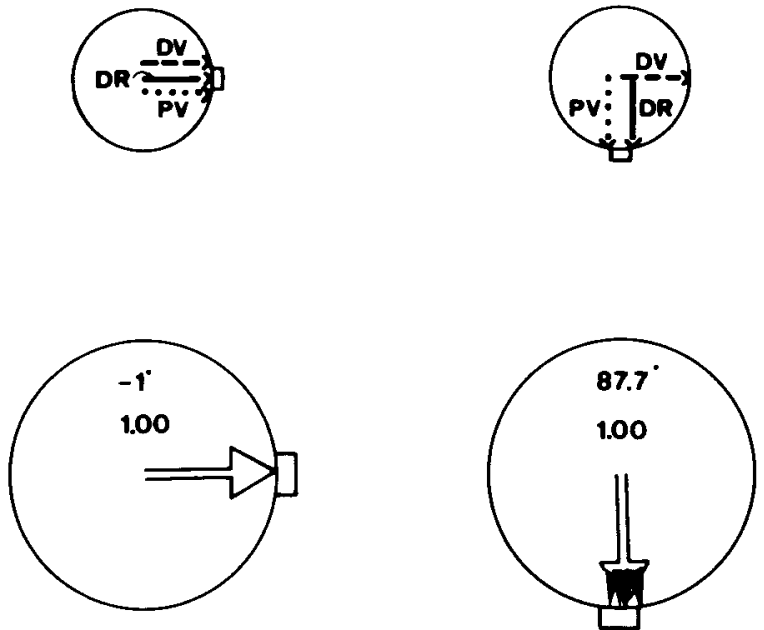

$-90^{\circ}$
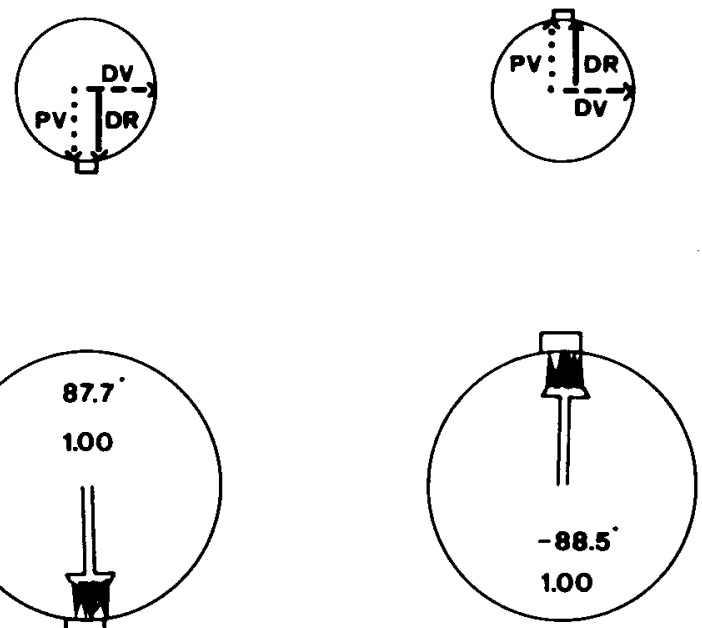

Figure 9. Return directions during attainment of the learning criterion in Experiment 2. On the large circles, the large open vector represents the mean homing direction of 6 subjects during eight control and during four experimental trials (second-order statistics, $p<.001$; Moore's test). On the two circles to the right, each full arrowhead represents the mean homing direction of 1 subject during four experimental trials (first-order statistics, $p<.01$; Rayleigh test). For further explanations, see the caption of Figure 5.

return journey, both because of improved correction maneuvers along the arena wall and changes in the initial homing direction (see Figure 10).

During the consolidation period, in which each subject underwent three additional test series, the animals failed to compensate for the nest rotation correctly in only 3 out of a total number of 72 experimental trials. This means that, in general, the subjects returned to the rotated nest throughout five consecutive test series, including a total of 20 experimental trials.

On the whole, the comparison between the data from Experiments 1 and 2, which were obtained in identical conditions except for the presence of the proximal cue card, yields the following differences: (1) Whereas only 4 out of 6 subjects reached the learning criterion in Experiment 1, this was the case for all 6 subjects of Experiment 2; (2) in Experiment 2, the learning criterion was reached significantly sooner than in Experiment $1\left(U=0, n_{1}=4\right.$, $n_{2}=6, p<.005$; Mann-Whitney $U$ test); and (3) at the beginning of the training period, the return times were significantly shorter in Experiment 2 than in Experiment 1 (first test series, $U=2, p<.02$; second test series, $U=0, p<.005$ ).

A final step in the experiments with the cue card around the nest entrance consisted in removing the cue card or establishing a threefold dissocation between the spatial information originating from distal room cues, the cue card, and dead reckoning. After they reached the learning criterion and performed in a number of consolidation trials, the 6 subjects of Experiment 2 underwent 2 trials of each of the three types of superexperimental tests (see Figure 11$)$. In dissociation procedure a $\left(90^{\circ}\right.$ rotation of arena and $180^{\circ}$ rotation of cue card with respect to the $0^{\circ}$ reference direction), the subjects returned mainly toward the (rotated) nest entrance or at least toward the $90^{\circ}$ sector centered on the nest entrance ( 8 trials), and in a minority of trials returned toward the $90^{\circ}$ sector centered on the cue card ( 2 trials). In procedure $b$, the arena

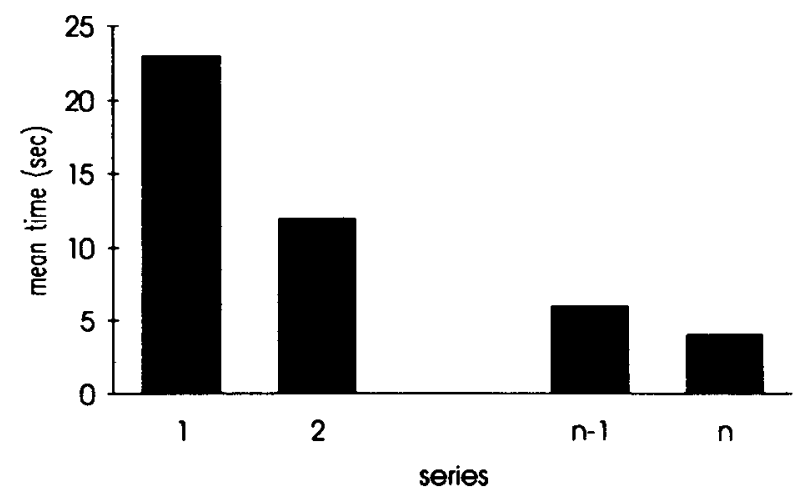

Figure 10. Return times at the beginning and end of training in Experiment 2. The histograms represent the mean duration of the return paths performed by 6 subjects during the experimental trials of the first two and the last two test series. There is a significant difference between the mean return times in the first two and the last two test series (Wilcoxon matched-pairs signed-ranks test: $n=6$, $t=0, p<.05$ ). 


\section{a}

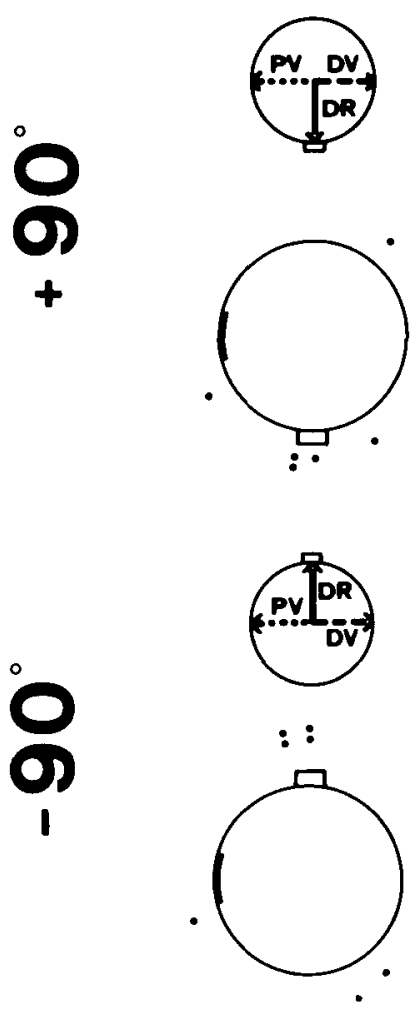

b
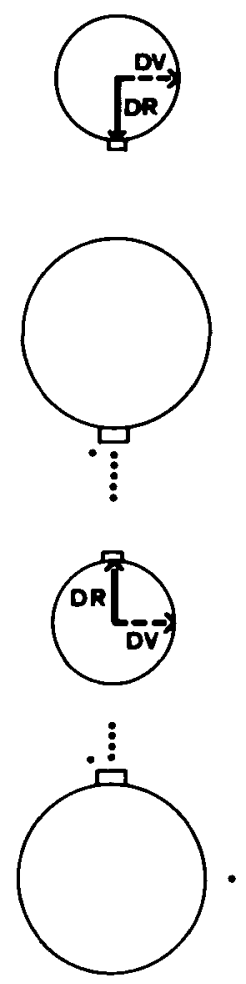

C
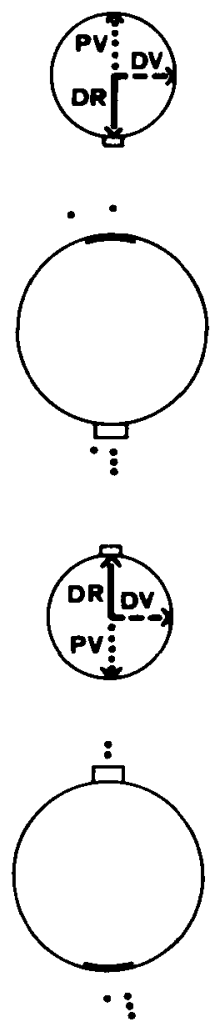

Figure 11. Return directions during the superexperimental trials in Experiment 2. The columns a, b, and c refer to the three types of superexperimental trials. The circles on the upper (lower) part of the figure refer to trials after a clockwise (counterclockwise) rotation of the arena and nest box. The arrows on the small circles represent the theoretical homing directions that the subjects would follow if they relied on distal visual cues (DV), on the proximal cue card (PV), or on dead reckoning (DR). The $30^{\circ}$ arc inside the large circles of columns a and $c$ indicate the cue card on the arena wall. On the large circles, the dots indicate in which $10^{\circ}$ sector each subject entered the peripheral annular zone of the arena during one superexperimental trial.

was rotated by $90^{\circ}$, and the cue card was removed. In this situation, the great majority of return journeys occurred toward the actual, rotated nest (11 trials), with one return toward the standard nest location. Finally, in procedure $c$, the arena and cue card were rotated (by $90^{\circ}$ ) in opposite directions with respect to the $0^{\circ}$ reference direction, so that the nest entrance and the cue card were located opposite to each other. Now, an equal number of return paths were directed toward the nest ( 6 trials) and toward the cue card (6 trials).

The coding of the animals' position and orientation before they initiated the homing path at the arena center showed that in all cases in which the subjects aimed their return directly at the cue card, they were facing the card before their departure. Systematic tendencies in the animals' orientation before they started to return toward the actual or standard nest location were not observed.

In summary, Experiment 2 shows that hamsters easily learned to return consistently to the rotated nest position when the nest entrance was marked by a conspicuous cue card. The animals that had learned to return toward the rotated nest in these conditions maintained this behavior when the cue card was removed. In dissociation experiments in which dead reckoning, proximal, and distal visual cues yielded three different homing directions, the animals relied mainly on dead reckoning (return to the rotated nest), less frequently on the cue card (return toward the card), and only very seldom on distal visual room cues (return to standard nest position). On the whole, it seems, therefore, that the proximal cue card, which remained always correlated with dead reckoning and thus with the nest, significantly helped the animals to detach themselves from the influence of distant visual cues.

\section{SUPPLEMENTARY EXPERIMENT 2}

Experiment 2 was preceded by earlier tests. During three distinct test periods, three groups of hamsters had 
been trained according to procedures very similar to those in Experiment 2, with the cue card around the nest entrance. For a fourth experimental group, the cue card was no longer superimposed on the nest entrance but located at an angular distance of $90^{\circ}$ from it. The results of these original tests agree with the main data of Experiment 2 and will be summarized briefly.

\section{Method}

Subjects. The four above-mentioned experimental groups included 4 subjects each. These subjects differed among themselves and from the subjects of Experiments 1 and 2 in the amount of former test experience.

Procedures. The training conditions differed from those of Experiment 2 with respect to the following points: (1) During the experimental trials, the rotated arena was not left in its new position until the subject had reached the nest entrance (or for a maximal time span of $3 \mathrm{~min}$ ), but was rotated back to its standard position shortly after the subject had reached the arena periphery; (2) the original arena had a higher peripheral wall (the upper border was $61 \mathrm{~cm}$ above the room floor) than did the arena used in Experiments 1 and 2 , and the white cue card $\left(30^{\circ}\right.$ width) again covered the whole height of the wall; and (3) the return paths of the animals were coded with respect to twelve $30^{\circ}$ sectors (instead of thirtysix $10^{\circ}$ sectors). Two of these initial experimental groups (a total of 8 subjects) were submitted to superexperimental trials of Type a (the cue card is at an angular position of $180^{\circ}$, and the nest entrance is at a position of $90^{\circ}$ from the usual nest location).

One further group of 4 subjects was trained according to the same procedures, with a cue card located $90^{\circ}$ counterclockwise from the nest entrance. These subjects were not submitted to superexperimental trials.

\section{Results and Discussion}

In the very first experimental trial of the supplementary experiments, our former subjects showed the same behavior pattern as did the subjects in Experiment 2that is, they showed compromise behavior, heading mainly toward the standard nest location, but also showing a directional bias toward the new nest location. Thereafter, in general, the animals learned slightly more slowly than did those in Experiment 2 and reached the learning criterion after a mean number of 33.7 (range: 8-60) experimental trials. The greater number of trials that some of the subjects needed to give priority to the combination of dead reckoning and the intramaze cue, in contrast to the Subjects of Experiment 2, can be explained by the main difference in the training procedures: According to our initial procedures, the arena remained in its new, rotated position for a relatively short time, so the animals had not necessarily reached the nest entrance before it was rotated back to its standard position. In Experiment 2, on the contrary, most of the subjects had reentered the nest entrance before its standard position was reinstated.

Two of our initial experimental groups (a total of 8 subjects) were also submitted to consolidation and superexperimental (Type a) trials after having reached the learning criterion. During the superexperimental trials, the subjects of one group returned almost always toward the (rotated) nest. In contrast, the animals from another group returned to the white cue card (four trials) as well as to the nest (three trials).
Finally, one group of subjects was tested according to our initial procedures, with a cue card that was positioned at an angular distance of $90^{\circ}$ (counterclockwise) from the nest entrance. The subjects of this group reached the learning criterion after $4,52,60$, and 116 experimental trials (mean: 58 trials). Thus, the fact that the intramaze cue was no longer superimposed on the nest entrance, and therefore could not guide the subjects directly to their goal, lengthened the learning period, albeit not significantly so.

On the whole, these data confirm the results of Experiment 2 and show that through their association, dead reckoning and the cue card always gain priority over distal room cues, even if the cue card no longer designates the goal directly.

\section{GENERAL DISCUSSION}

The strong impact that distal visual configurations exert on the homing directions of our subjects before the beginning of training (see Figure 2) has been noted in the literature on spatial orientation in rodents and other species. These cues are normally associated with stable features of the general environment; therefore, in laboratory conditions, distal configurations may also be associated with the general shape of the test room (Cheng, 1986; Margulis \& Gallistel, 1988). Dead reckoning, on the other hand, depends at least partially on inertial signals and therefore informs the organism of changes in its location and heading with respect to absolute space. Since the structure of the test room usually does not vary in relation to absolute space, distal visual configurations and dead reckoning tend to remain correlated. In our experimental conditions, however, this correlation was broken by letting the subjects initiate path integration at an unusual place, apparently without their knowledge. The spontaneous preference that hamsters show in these conditions for distal visual configurations may be explained by differences in the reliability and stability of route- and location-based information: Dead reckoning is open to cumulative errors and its outcome is stored in short-term memory, whereas associations between stable visual landmarks and locations or directions are stored on a long-term basis and can always be controlled through visual feedback (Etienne, 1987).

Let us not forget, however, that in our test conditions the influence of dead reckoning always remained noticeable, whatever the impact of the visual scenario. Thus, in Figure 2, only 2 out of 6 subjects returned precisely to the former location of the nest entrance, whereas the mean homing direction of the whole experimental group expressed a (slight) compromise between dead reckoning and the distant visual environment. Compromise directions have often been observed in our research and reflect simultaneously the relative weight of each source of information and the degree of conflict that derives from uncorrelated spatial information (Etienne, Teroni, Hurni, \& Portenier, 1990).

In the light of our former data (see, e.g., Teroni et al., 1987), the result that most of our subjects learned not only to increase the compromise between different sets of cues, 
but also to invert the priority of visual location-based over internal route-based references (see Figures 4, 5, and 6) was rather unexpected. It shows that hamsters are capable of changing the order of importance that they normally give to certain classes of spatial information. On the other hand, 2 out of 6 hamsters that fulfilled the training conditions failed to reach the learning criterion in Experiment 1 (see Figure 3). One of these animals did not free herself from the impact of the distant visual environment, and the other ended up with a constant directional bias. Furthermore, we may question whether the subjects that had learned to depend on dead reckoning after a mean number of $67 \mathrm{ex}$ perimental trials would have maintained the learning criterion over a more extended test period (see p. 270). Thus, Experiment 1 imposed on our subjects changes in the spontaneous preference for certain references that seemed to approach the limits of their flexibility in the choice of relevant spatial information.

According to an alternative explanation of the learning process that took place in Experiment 1, the subjects could have used visual route-based information to return to the rotated nest-instead of relying on internal signals as they do in darkness, the animals might have learned, for instance, that during their return to the arena periphery, they must invert the relationship between the axis of their progression and certain room cues that they have observed during the outward journey to the food source. Thus, if they moved toward a set of cues during the outward journey to the center of the arena, they have to move away from these cues during the return to the periphery. However, former experiments that tested the hamsters' readiness to use visual references in this manner speak against this hypothesis-hamsters that were presented with a directional visual reference during the outward journey to the feeding place did not seem to use this reference in a route-based manner to return to their nest (Etienne et al., 1990).

Furthermore, the observation of "inversions" (i.e., compensations of the arena rotation that occurred in the wrong direction) may seem to not fit in readily with our interpretation that the subjects learned to rely on dead reckoning rather than on distal room cues: To return to the nest, the hamsters may have learned to walk away from certain visual landmarks, independently of the preceding outward journey. This hypothesis may explain the consistent directional bias shown by 1 subject that failed to reach the learning criterion (see Subject 2 in Figure 3), as well as phases in the learning process in which all experimental returns deviated in the same sense from the $0^{\circ}$ reference direction (see Subject 3 on Figure 4). Without making additional assumptions, however, we cannot explain along these lines how successful learners were able to chose three different homing directions during the control and experimental trials.

Experiment 2 yielded significantly more positive results than did Experiment 1. Even during the first experimental trial, the proximal cue card that was rotated with the arena and nest box reinforced the role of dead reckoning and therefore increased the compromise between the usual and actual direction of the nest entrance (see Figure 7). During training, the subjects of Experiment 2 quickly started to compensate for the arena rotation and reached the learning criterion after a mean number of 24 experimental trials (see Figures 8, 9, and 10). Similar results are reported under the heading of Supplementary Experiment: In former experiments with 12 subjects, all of the animals learned to ignore distant room cues despite the fact that the arena was not left in its new position until they had reached the (rotated) nest entrance.

The effect of the conspicuous card was especially pronounced when it designated the nest entrance and therefore acted as a beacon. However, the cue card also enhanced the learning process of 4 subjects when it was located at an angular distance of $90^{\circ}$ from the nest entrance (see p. 277). The importance of nearby, conspicuous landmarks for relocating specific places has been described for a number of hymenopteran insects (Cheng, Collet, Pickhard, \& Wehner, 1987; also see Wehner, 1981), fish (Warburton, 1990), birds (Cheng, 1989; also see Sherry, 1984), and rodents (Collett, Cartwright, \& Smith, 1986; Mackintosh, 1973).

During the final dissociation trials ( $a$ and $c$ ) of Experiment 2 , in which dead reckoning, and distal and proximal visual cues indicated three different homing directions, the animals depended mainly on dead reckoning, less often on the proximal cue card and rarely on the distal visual environment (see Figure 11 ). It seems, therefore, that under conflicting visual conditions, and through its prior association with the proximal cue card, dead reckoning became the main criterion for homing. This was also suggested by the fact that the subjects had to face the card before their departure at the arena center in order to return toward it and that they did not always aim their approach directly at the card. Furthermore, the hamsters persisted in returning to the rotated nest when the cue card had been removed. However, we did not carry out complementary test trials by maintaining the cue card and jamming dead reckoning, a measure that can be achieved by rotating the subject on a horizontal platform at the end of the outward journey (Etienne, Maurer, \& Saucy, 1988; Etienne et al., 1990). In these conditions the animals probably would have directed their return path toward the cue card, whatever its position. The dissociation experiments do in fact illustrate that after their mutual association, the proximal visual cue as well as dead reckoning alone cancel out the influence of the distal visual environment.

In the psychological literature, experiments on maze learning that involved either the rotation of a maze or the permutation of its components have shown repeatedly that rats continue to rely on the extramaze environment in these conditions (Kraemer, Gilbert, \& Innis, 1983; Olton \& Collison, 1979; Olton, Collison, \& Werz, 1977; Olton \& Samuelson, 1976). Similarly, these animals follow the rotation of controlled extramaze cues, provided that the topological relations between these cues are preserved (Suzuki, Augerinos, \& Black, 1980). These results are fully supported by single-unit recordings in intact rats that were tested in the presence of stimuli from within and 
outside the test apparatus. Under these conditions, the place field of hippocampal complex spike units remained constant when the maze was rotated (Hill \& Best, 1981; Miller \& Best, 1980), was not influenced by the interchange of the maze arms, and followed the rotation of controlled extramaze cues (O'Keefe \& Conway, 1978).

Convergent data of this nature point toward the abovementioned functional supremacy of extramaze cues and have only seldom been contradicted by empirical evidence obtained within a different theoretical framework such as discrimination learning or Pavlovian conditioning (DiezChamizo, Sterio, \& Mackintosh, 1985; March, Chamizo, \& Mackintosh, 1992). In the context of our research on dead reckoning, we would like to emphasize that as long as the experimental procedures (e.g., the rotation of the maze or of a controlled background) maintain the geometrical relationships between extramaze cues, they also preserve the positive correlation between these cues and dead reckoning. Dead reckoning may therefore enhance the spatial signification of distal cues, provided that the experimental conditions allow the animals to keep track of their locomotion.

On the other hand, there is general agreement that rats learn to master a maze on the basis of salient internal cues when adequate extramaze cues are not available (Hughey \& Koppenaal, 1987; Kraemer et al., 1983; Restle, 1956). Again, neuropsychological data point in the same direction: A conspicuous intramaze card, similar to the one used in our research, that is presented in the absence of any other cue from the proximal or distant visual environment can polarize the firing field of a single place cell. Thus, rotations of the cue card produce equal rotations of the units' place field (Breeze, Hampson, \& Deadwyler, 1989; Muller \& Kubie 1987; Muller, Kubie, Bostock, Taube, \& Quirk, 1991).

In contrast to other research, the conditions of Experiment 2 were set so that dead reckoning was in conflict with the extramaze environment but remained correlated with an intramaze cue. During their excursions away from the nest, dead reckoning is bound to inform the subjects about their successive locations and headings with respect to the nest entrance. On the basis of this information, the animals may at any moment have expected to view particular configurations from the familiar environment under a given angle and at a given distance. During the rotation of the arena, the intramaze cue alone confirmed this expectation, and therefore gained the status of an exclusive visual reference.

\section{REFERENCES}

Batschelet, E. (1981). Circular statistics in biology. London: Academic Press.

Breeze, C. R., Hampson, R. E., \& Deadwyler, S. A. (1989). Hippocampal place cells: Stereotypy and plasticity. Journal of Neuroscience, 9, 1097-1111.

Cheng, K. (1986). A purely geometric module in the rat's spatial representation. Cognition, 23, 149-178.

Cheng, K. (1989). The vector sum model of pigeon landmark use. Jour- nal of Experimental Psychology: Animal Behavior Processes, 15. 366-375.

Cheng, K., Collett, T. S., Pickhard, A., \& Wehner, R. (1987) The use of visual landmarks by honeybees: Bees weight landmarks according to their distance from the goal. Joumal of Comparative Physiology $A, 161,469-475$.

Collett, T. S., Cartwright, B. A., \& Smith, B. A. (1986). Landmark learning and visuo-spatial memories in gerbils. Journal of Comparative Physiology A, 158, 835-851.

Diez-Chamizo, V., Sterio, D., \& Mackintosh, N. J. (1985). Blocking and overshadowing between intra-maze and extra-maze cues: A test of the independence of locale and guidance learning. Quarterly Journal of Experimental Psychology, 37B, 235-253.

ETIENNE, A. S. (1987). The control of short distance homing in the golden hamster. In P. Ellen \& C. Thinus-Blanc, (Eds.), Cognitive processes and spatial orientation in animal and man (pp. 233-251). Dordrecht, The Netherlands: Martinus Nijhoff.

ETIENNE, A. S. (1992). Navigation of a small mammal by dead reckoning and local cues. Current Directions in Psychological Science, $1,48-52$

Etienne, A. S., Maurer, R., \& Saucy, F. (1988). Limitations in the assessment of path dependent information. Behaviour, 106, 81-111.

Etienne, A. S., Maurer, R., Saucy, F., \& Teroni, E. (1986). Shortdistance homing in the golden hamster after a passive outward journey. Animal Behaviour, 34, 696-715.

etienne, A. S., Teroni, E., Hurni, C., \& Portenier, V. (1990). The effect of a single light cue on homing behaviour of the golden hamster. Animal Behaviour, 39, 17-41.

Gallistel, C. R. (1990). The organization of learning. Cambridge, MA: MIT Press

HiLL, A. J., \& BEST, P. J. (1981). Effects of deafness and blindness on the spatial correlates of hippocampal unit activity in the rat. $E x$ perimental Neurology, 74, 204-217.

Hughey, D. J., \& KopPenaAl, R. J. (1987). Hippocampal lesions in rats alter learning about intramaze cues. Behavioral Neuroscience, 101, 634-643.

Kraemer, P. J., Gilbert, M. E., \& Innis, N. K. (1983). The influence of cue type and configuration upon radial-maze performance in the rat. Animal Learning \& Behaviour, 11, 373-380.

LEONARD, B., \& MCNAUGHTON, B. L. (1990). Spatial representation in the rat: Conceptual, behavioral, and neurophysiological perspectives. In R. P. Kesner \& D. S.Olton (Eds.), Neurobiology of comparative cognition (pp. 363-422). Hillsdale, NJ: Erlbaum.

Mackintosh, J. H. (1973). Factors affecting the recognition of territory boundaries by mice (Mus musculus). Animal Behaviour, 21 , 464-470.

March, J., Chamizo, V. D., \& Mackintosh, N. J. (1992). Reciprocal overshadowing between intra-maze and extra-maze cues. Quar terly Journal of Experimental Psychology, 45B, 49-63.

Margulis, J., \& Gallistel, C. R. (1988). Heading in the rat: Determination by environmental shape. Animal Learning \& Behavior, 16, 404-410.

Miller, V. A., \& Best, P. J. (1980). Spatial correlates of hippocampal unit activity are altered by lesions of the fornix and entorhinal cortex. Brain Research, 194, 311-323.

MittelstaedT, H., \& MitTelstaedT, M.-L. (1982). Homing by path integration. In F. Papi \& H. G. Wallraff (Eds.), Avian navigation (pp. 290-297). Berlin: Springer.

MUlLER, R. U., \& KUBIE, J. L. (1987). The effects of changes in the environment on the spatial firing of hippocampal complex-spike cells. Journal of Neuroscience, 7, 1951-1968.

Muller, R. U., Kubie, J. L., Bostock, E. M., Taube, J. S., \& QUIRK, G. J. (1991). Spatial firing correlates of neurons in the hippocampal formation of freely moving rats. In J. Paillard (Ed.), Brain and space (pp. 296-333). Oxford: Oxford University Press.

O'KeEFE, J., \& CONWAY, D. H. (1978). Hippocampal place units in the freely moving rat: Why they fire where they fire. Experimental Brain Research, 31, 573-590.

O'KeEFE, J., \& NADEL, L. (1978). The hippocampus as a cognitive map. London: Clarendon Press. 
Olton, D. S. (1979). Mazes, maps, and memory. American Psychologist, 34, 583-596.

OLTON, D. S. (1990). Spatial perception: Behavioral and neural analyses. In C. Stebbins \& M. A. Berkley (Eds.), Comparative perception: Complex signals (Vol. 2, pp. 217-244). New York: Wiley.

Olton, D. S., \& Coluson, C. (1979). Intramaze cues and "odor trails" fail to direct choice behavior on an elevated maze. Animal Learning \& Behavior, 7, 221-223.

Olton, D. S., Collison, C., \& Werz, M. A. (1977). Spatial memory and radial arm maze performance of rats. Learning \& Motivation, 8, 289-314.

Olton, D. S., \& SAMUELSON, R. J. (1976). Remembrance of places passed: Spatial memory in rats. Journal of Experimental Psychology: Animal Behavior Processes, 2, 97-116.

RESTLE, F. (1956). Discrimination of cues in mazes: A resolution of the "place-vs.-response" question. Psychological Review, 64, 217-288.

Sherry, D. V. (1984). What food-storing birds remember. Canadian Journal of Psychology, 38, 304-321.

SIEGEL, S. (1956). Nonparametric statistics for the behavioral sciences. New York: McGraw-Hill.
Suzuki, S., Augerinos, G., \& Black, A. H. (1980). Stimulus control of spatial behavior on the eight-arm maze in rats. Learning \& Motivation, 11, 1-18.

Teroni, E., Portenier, V., \& Etienne, A. S. (1987). Spatial orientation of the golden hamster in conditions of conflicting location-based and route-based information. Behavioral Ecology \& Sociobiology, 20, 389-397.

Warburton, K. (1990). The use of local landmarks by foraging goldfish. Animal Behaviour, 40, 500-505.

WATsON, J. B. (1907). Kinesthetic and organic sensations: Their role in the reaction of the white rat to the maze. Psychological Review Monograph Supplements, 8(Whole No. 33), 1-100.

WEHNER, R. (1981). Spatial vision in arthropods. In H. Autrum (Ed.), Handbook of sensory physiology (Vol. VIl/6C, pp. 287-616). Berlin: Springer.

(Manuscript received June 19, 1992; revision accepted for publication January 24, 1993.) 